\title{
Migrânea durante a gestação - perfil clínico
}

\author{
Mauro Eduardo Jurno', Dilermando Fazito de Rezende ${ }^{2}$, Érica Cristina de Almeida Pereira ${ }^{3}$, \\ Gustavo Henrique Souza Rocha ${ }^{3}$, Janaíne Coelho ${ }^{3}$, Laíza de Castro Alvarenga ${ }^{3}$, Naiana Ribeiro Borges ${ }^{3}$ \\ ${ }^{7}$ Neurologista, professor da Faculdade de Medicina de Barbacena; ${ }^{2}$ Estatístico, professor da Faculdade de \\ Medicina de Barbacena; ${ }^{3}$ Alunos da Faculdade de Medicina de Barbacena, MG \\ Jurno ME, Rezende DF, Pereira EC, Rocha GH, Coelho J, Alvarenga LC, Borges NR. Migrânea durante a \\ gestação - perfil clínico. Headache Medicine. 2012;3(4):210-1
}

\section{INTRODUÇÃO}

Um dos fatores que podem influenciar o quadro de migrânea nas mulheres são as alterações hormonais observadas durante a gravidez. Estudos evidenciam que a maioria das mulheres grávidas que apresentavam cefaleia pré-gestacional exibiu melhora ou desaparecimento da mesma durante a gestação, especialmente quando se refere à migrânea menstrual.

\section{OBJETIVO}

Relacionar a frequência da migrânea com os trimestres gestacionais das pacientes, que foram admitidas no âmbito ambulatorial em uma clínica de pré-natal, e comparar com a incidência das crises de cefaleia no período pré-gravidez.

\section{MATERIAIS E MÉTODOS}

O trabalho constou em um estudo de corte transversal, realizado mediante uma entrevista sobre enxaqueca em gestantes que apresentaram cefaleia no período anterior ou durante a gestação. Essas foram diagnosticadas como portadoras de migrânea, através dos critérios da Classificação Internacional. O presente estudo foi realizado no período entre julho de 2011 e fevereiro de 2012, em um grupo de 200 gestantes que aceitaram participar do estudo, com idade entre 18 e 50 anos e se encontravam no terceiro trimestre de gestação. As participantes foram selecionadas sequencialmente entre todas as gestantes que compareceram ao serviço ambulatorial e preencheram os critérios de inclusão. A análise estatística foi realizada com os recursos de processamento estatístico do Software Stata 9.2.; foram construídas as distribuições de frequência e calculadas as porcentagens médias e desvio padrão indicados para cada variável. As proporções foram comparadas em tabelas de contigência RxC e as médias em tabelas de Anova.

No tocante aos aspectos éticos não houve conflitos de interesse, e a pesquisa foi aprovada pelo Comitê de Ética em Pesquisa da UNIPAC (CEP-UNIPAC) sob o $n^{\circ}$ $828 / 2011$.

\section{RESULTADOS}

O grupo foi composto por 200 pacientes, onde se observou que $82(41,0 \%)$ eram migranosas e as restantes 118 (59,0\%) não preenchiam os critérios para diagnóstico de migrânea. As comparações de portadoras ou não de migrânea segundo a faixa etária são apresentadas na Tabela 1. As pacientes migranosas e não migranosas apresentaram idade média igual a 28,3 e 26,3 anos, respectivamente. Os resultados observados sobre a evolução da dor de cabeça durante os trimestres da gestação em relação ao período pré-gestacional estão representados na Tabela 2. A comparação das crises de

\begin{tabular}{ccccc} 
Tabela 1 - Faixa etária das pacientes migranosas e não migranosas \\
\hline \multirow{2}{*}{$\begin{array}{c}\text { Grupo etário } \\
\text { (anos) }\end{array}$} & \multicolumn{2}{c}{ Não migranosas } & \multicolumn{2}{c}{ Migranosas } \\
\cline { 2 - 5 } & $\mathrm{N}$ & $\%$ & $\mathrm{~N}$ & $\%$ \\
\hline $18-25$ & 64 & 54,3 & 32 & 39,0 \\
$26-46$ & 54 & 45,7 & 50 & 61,0 \\
\hline
\end{tabular}

$\chi^{2} / F=4,49 ; P=0,034$

Tabela 2 - Evolução da dor observada durante a gestação das pacientes migranosas em relação ao período pré-gestacional

\begin{tabular}{ccccccc}
\hline \multirow{2}{*}{ Trimestre } & \multicolumn{2}{c}{ Melhorou } & \multicolumn{2}{c}{ Piorou } & \multicolumn{2}{c}{ Inalterado } \\
\cline { 2 - 7 } & N & $\%$ & N & $\%$ & N & $\%$ \\
\hline I & 17 & 20,7 & 36 & 43,9 & 29 & 35,4 \\
II & 35 & 42,7 & 22 & 26,8 & 25 & 30,5 \\
III & 45 & 54,9 & 15 & 18,3 & 22 & 26,8 \\
\hline
\end{tabular}


migrânea quando classificadas se melhoraram, pioraram ou mantiveram inalteradas, no terceiro trimestre da gestação em relação ao primeiro, se encontram descritas na Tabela 3.

Tabela 3 - Comparação da dor observada no terceiro trimestre da gestação em relação ao primeiro nas pacientes migranosas

\begin{tabular}{ccccccc}
\hline \multirow{2}{*}{$\begin{array}{c}\text { Primeiro } \\
\text { Trimestre }\end{array}$} & \multicolumn{2}{c}{ Melhorou } & \multicolumn{2}{c}{ Piorou } & \multicolumn{2}{c}{ Inalterado } \\
\cline { 2 - 7 } & $\mathrm{N}$ & $\%$ & $\mathrm{~N}$ & $\%$ & $\mathrm{~N}$ & $\%$ \\
\hline I & 15 & 33,3 & 1 & 6,7 & 1 & 4,5 \\
II & 18 & 40,0 & 8 & 53,3 & 10 & 45,5 \\
III & 12 & 26,7 & 6 & 40,0 & 11 & 50,0 \\
\hline
\end{tabular}

$\chi^{2} / F=10,52 ; P=0,033$

\section{DISCUSSÃO}

A gravidez altera substancialmente a enxaqueca, já que geralmente irá reduzir a frequência e severidade das crises de migrânea, devido à relação entre o aumento do estrogênio e a melhora da cefaleia. Os resultados obtidos neste trabalho relacionando as pacientes migranosas com os trimestres investigados condizem com relatos da literatura, em que as crises de enxaqueca, muitas vezes, têm a frequência aumentada no primeiro trimestre, mas se espera diminuir nos segundo e terceiro trimestres da gravidez.

\section{CONCLUSÃO}

Os dados obtidos com a realização do nosso trabalho estão em concordância com estudos anteriormente apresentados, nos quais foi demostrada uma diminuição gradual de dores de cabeça ao longo dos três trimestres de gestação. Acreditamos que os resultados obtidos com esse estudo ajudarão as próprias pacientes a avaliarem sua qualidade de vida e aos profissionais da área a orientar e entender melhor suas pacientes.

\section{REFERÊNCIAS}

Kvisvik EV et al. Headache and migraine during pregnancy and puerperium: the MIGRA-study. J Headache Pain (2011) 12: 443-51.

Melhado EM. Cefaleia na gestação. [Tese].Campinas: Faculdade de Ciências Médicas da Universidade Estadual de Campinas; 2005.

Melhado EM. Cefaleia na mulher. Rio de Janeiro: Atheneu, 2011.

Melhado E, Maciel JJA, Guerreiro CAM. Headaches during pregnancy in women with a prior history of menstrual headaches. Arq Neuropsiquiatr 2005;63(4):934-940.

Serva WAD et al. Course of migraine during pregnancy among migraine sufferers before pregnancy. Arq Neuropsiquiatr 2011 ; 69(4):613-9.

Subcomitê de Classificação das Cefaléias. Classificação Internacional das Cefaléias. $2^{a}$ ed. São Paulo: Alaúde Editorial; 2004. 